\title{
Níveis de Feno de Alfafa e Forma Física da Ração no Desempenho de Cordeiros em Creep Feeding
}

\section{Marcela Abbado Neres ${ }^{1,2}$, Cledson Augusto Garcia ${ }^{3}$, Alda Lúcia Gomes Monteiro3 Ciniro Costa ${ }^{4}$, Antônio Carlos Silveira ${ }^{4}$, Guilherme Jordão Magalhães Rosa ${ }^{5}$}

\begin{abstract}
RESUMO - Com o objetivo de avaliar o desempenho de cordeiros em creep feeding e confinados, foram realizados dois experimentos No primeiro, 32 cordeiros $3 / 4$ mestiços Suffolk foram criados em creep feeding, desmamados aos 56 dias de idade e, em seguida, confinados Os cordeiros receberam os seguintes tratamentos: 1 . sem suplementação; 2 . suplementação com ração à base de milho e soja; 3 . ração à base de milho e soja com $15 \%$ de feno de alfafa; 4. ração à base de milho e soja com 30\% de feno de alfafa. Após o desmame, os cordeiros suplementados foram confinados, recebendo a mesma ração do creep feeding até atingirem de 30 a $32 \mathrm{~kg}$ de peso vivo. No segundo experimento, foram utilizados 32 cordeiros $3 / 4$ mestiços Suffolk, alimentados em creep feeding, recebendo ração farelada ou peletizada até os pesos de abate: 26 e $28 \mathrm{~kg}$. As dietas eram isoprotéicas (21\% PB) e isoenergéticas (2,9 Mcal EM/kg MS). Os animais suplementados na fase de aleitamento obtiveram ganho de peso de 147,4g/dia a mais, quando comparados aos não suplementados. Não houve efeito dos níveis de feno de alfafa na ração sobre o desempenho dos animais. Entretanto, no confinamento, a máxima eficiência de ganho de peso esperada para os machos, conforme a análise de regressão, situou-se em $18,7 \%$ de inclusão de feno de alfafa na ração. A ração peletizada propiciou maior desenvolvimento dos animais, quando comparada à ração farelada. Os machos que receberam ração peletizada atingiram os pesos de abate de 26 e $28 \mathrm{~kg}$ aos 55 e 60 dias de idade, respectivamente.
\end{abstract}

Palavras-chave: cordeiros, creep feeding, peletização

\section{Alfalfa Hay Levels and Diet Physical Form on Lambs Performance on Creep Feeding}

ABSTRACT - Lambs performance fed on creep feeding and fedlot were evaluated at two experiments. In the first experiment, thirty two 3/4 Suffolk lambs were fed on creep feeding, weaned at 56 days of age and, after, were confined. Lambs were fed four different treatments: 1 . without supplemmentation; 2 . supplemmentation with ground corn and soybean meal; 3 . ground corn, soybean meal and $15 \%$ alfalfa hay; 4 . ground corn, soybean meal and $30 \%$ alfalfa hay. After weaning, lambs that received concentrate supplemmentation were confined with the same diet until 30-32 kg live weight. In the second experiment, thirty two 3/4 Suffolk lambs were fed on creep feeding with pelleted and ground diets until to reach 26 or $28 \mathrm{~kg}$ live weight to be slaughtered. Diets were isoprotein ( $21 \% \mathrm{CP})$ and isoenergetic (2.9 Mcal ME/kg DM). Lambs supplemmented during suckling time presented higher live weight gain (plus $147.4 \mathrm{~g} / \mathrm{d}$ ) than non supplemmented ones. Alfalfa hay levels did not affect lambs performance. However, on the feedlot, the maximum efficiency expected for males weight gain, according to regression analysis, would be $18.7 \%$ of alfalfa hay added to ration. Better lambs performance was observed with pelleted diets compared to ground ones. Males fed pelleted diets reached 26 and $28 \mathrm{~kg}$ of slaughter weight at 55 and 60 days old, respectively.

Key Words: lambs, creep feeding, pelletization

\section{Introdução}

A deficiência de energia na dieta é a principal causa na redução do desenvolvimento ponderal do cordeiro lactente, principalmente nas regiões onde a época de parição coincide com o período de escassez de forragem. Assim, a suplementação dos cordeiros lactentes afirma-se como uma prática de manejo prioritária e estratégica na produção de cordeiros, devendo ser iniciada logo após o nascimento, com a finalidade de adaptar os animais ao consumo de alimento sólido. Além disso, a qualidade da fibra torna-se um fator importante na dieta, tendo em vista que os cordeiros são mais suscetíveis à acidose aguda, quando comparados aos bovinos (HATFIELD et al., 1997).

Além da qualidade da dieta, os diversos sistemas de criação de ovinos destinados à produção de carne

\footnotetext{
1 Parte da tese de Doutorado do primeiro autor.

2 Professora do C.C.A., UNIOESTE, Mal. Cândido Rondon, PR. Rua Pernambuco, 1777. Cx. P. 91, CEP: 85960-000. E.mail: neresmg@fsnet.com.br

3 Professor da Faculdade de Ciências Agrárias da Universidade de Marília, Marília, SP. E.mail: adalgm@terra.com.br; cagarcia@unimar.br

4 Professor do Departamento de Nutrição e Melhoramento Animal/UNESP, Botucatu, SP. E.mail: secdmna@fca.unesp.br

5 Professor do Departamento de Bioestatística/UNESP, Botucatu, SP. E.mail: kiba@ibb.unesp.br
} 
têm influenciado não só o desempenho dos cordeiros, como também as características de carcaça.

McCLURE et al. (1994), avaliando os sistemas de terminação de cordeiros em pastagens e em confinamento, demonstraram a importância da alfafa no desempenho e nas características de carcaça de cordeiros. Em virtude de o desempenho e as características de carcaça dos animais terminados em pastagem de alfafa terem sido semelhantes aos obtidos com os animais confinados, os autores ressaltaram que esta superioridade da alfafa em relação às gramíneas Dactylis glomerata e azevém resultou do maior teor de $\mathrm{PB}$ e dos menores teores de FDN, FDA e hemicelulose da alfafa.

SAÑUDO et al. (1998) estudaram dois sistemas de produção de ovinos, em que, no primeiro, animais da raça Rasa Aragonesa foram desmamados com 38 a 40 dias e confinados e, no segundo, os animais permaneceram com as ovelhas até atingirem o peso de abate. Ambos os grupos receberam ração concentrada ad libitum e foram abatidos com $22,1 \mathrm{~kg}$ peso vivo, com idade média de 78 dias. Constatou-se que não houve diferença no ganho de peso entre os tratamentos, ficando ao redor de 222 e 232 g/dia, respectivamente; entretanto, os animais não desmamados apresentaram melhor rendimento de carcaça.

ORSKOV et al. (1971), ao compararem 20 cordeiros desmamados com $15 \mathrm{~kg}$ e abatidos com $40 \mathrm{~kg}$ recebendo pós-desmame cevada laminada ou milho, verificaram que os cordeiros tiveram ganho médio de 428 e $430 \mathrm{~g} /$ dia e conversão alimentar de 2,33 e 2,22, respectivamente.

O consumo de alimento pelos cordeiros entre duas e seis semanas de idade é afetado pela aceitabilidade, forma física da ração e pelas condições do creep feeding, que deve ser de fácil acesso e localizado próximo ao ponto preferencial de descanso do rebanho (NATIONAL RESEARCH COUNCIL - NRC, 1985). Até quatro semanas de idade, os cordeiros preferem ração farelada e, após quatro a cinco semanas, aceitam melhor as dietas peletizadas (NRC, 1985). CASEY e WEBB (1995) avaliaram dois níveis energéticos (médio 10,2 MJ $\mathrm{EM} \mathrm{kg} / \mathrm{MS}$ e alto $11,8 \mathrm{MJ} \mathrm{EM} \mathrm{kg} / \mathrm{MS}$ ) e duas formas de apresentação da ração (farelada e peletizada) sobre o desenvolvimento, composição de ácidos graxos e deposição de tecido adiposo subcutâneo em ovinos da raça Shorn. Os resultados sugerem que a ração peletizada de alta densidade energética pode reduzir o tempo de abate e limitar o acúmulo de ácidos graxos saturados e monoinsaturados no tecido adiposo subcutâneo, levando à melhor aceitação da carcaça pelo consumidor. Os animais que receberam ração farelada e de média energia apresentaram pior conversão alimentar $(5,77)$, enquanto os animais que receberam ração peletizada com alta energia tiveram melhor conversão $(4,36)$, indicando possibilidade de diminuição do custo de alimentação com a forma peletizada.

NICHOLS et al. (1992) avaliaram o ganho de peso de cordeiros que receberam ração em três sistemas; no primeiro, a ração era fornecida no sistema de livre escolha (ração à base de milho inteiro e feno de alfafa peletizado, fornecidos em recipientes separados); no segundo, a ração era composta de $30 \%$ de feno de alfafa peletizada e $70 \%$ de milho inteiro misturados; e no terceiro, a ração era à base de $30 \%$ de feno de alfafa e $70 \%$ de milho moído e peletizado. $O$ ganho de peso foi maior nos animais que receberam ração no sistema de livre escolha, que consistia da mistura de milho inteiro e alfafa peletizada. Os autores sugerem que a maior ingestão de matéria seca no sistema de livre escolha pode ter sido resultado da baixa acidose, devido à necessidade de maior mastigação. A relação de milho e alfafa na ração selecionada foi de 53:47.

Considerando que a densidade energética e a forma física da ração afetam o desempenho dos cordeiros, o trabalho objetivou estudar três níveis de feno de alfafa e a peletização da ração no desempenho de cordeiros alimentados em creep feeding.

\section{Material e Métodos}

No primeiro ano, avaliou-se o uso do creep feeding e níveis de feno de alfafa na ração dos cordeiros. No segundo ano, foi avaliada a forma física da ração nos cordeiros alimentados em creep feeding e dois pesos de abate.

No primeiro ano, o experimento foi dividido em duas fases: na primeira, avaliou-se o desempenho de cordeiros até o desmame, que ocorreu aos 56 dias de idade, alimentados em creep feeding; na segunda fase, após o desmame, os animais foram confinados até atingirem de 30 a $32 \mathrm{~kg}$ de peso vivo, quando os machos foram abatidos para avaliação de carcaça e as fêmeas mantidas para a reposição do plantel.

$\mathrm{Na}$ primeira fase, foram utilizadas 32 ovelhas com suas crias, 3/4 mestiços Suffolk, com parto simples, submetidas a um delineamento experimental inteiramente casualizado em esquema fatorial $(4 \times 2)$, sendo quatro tratamentos e dois sexos. Os tratamentos consistiam em: cordeiros sem acesso ao creepfeeding, 
com acesso à ração à base de milho e soja, cordeiros com acesso ao creep com a ração à base de milho e soja $+15 \%$ de feno de alfafa e cordeiros com acesso ao creep com a ração de milho e soja $+30 \%$ de feno de alfafa. Na Tabela 1, encontra-se a composição percentual e química das rações experimentais. Os valores de proteína bruta e energia metabolizável utilizados (NATIONAL RESEARCH COUNCIL NRC, 1985) para o cálculo de todas as rações foram: 8,7; 45 e 18\% PB e 3, 15; 3, 18; e 2,03 Mcal/EM/kg MS para milho, soja e feno de alfafa, respectivamente.

Foram utilizados quatro cordeiros inteiros e quatro cordeiras por tratamento. O período de nascimento foi de 18 de junho a 02 de julho de 1997. Após o nascimento, as crias foram pesadas e colocadas junto com as ovelhas em piquetes de gramínea estrela branca (Cynodon plectostachyus), com área de $2750 \mathrm{~m}^{2}$ cada um. As ovelhas receberam diariamente uma mistura concentrada com base em $1 \%$ do peso vivo fornecida em dois períodos e feno de Tifton 85 à vontade, para atender as exigências de ovelhas em lactação (NRC, 1985). As rações das crias foram fornecidas em duas refeições diárias (8 e $16 \mathrm{~h})$. As pesagens das crias e ovelhas foram realizadas a cada 14 dias, juntamente com a coleta de fezes para exame parasitológico (OPG).

Na segunda fase, as crias foram confinadas após o desmame (56 dias de idade), com peso vivo médio

Tabela 1 - Composição percentual e teores de proteína bruta (PB) e energia metabolizável (EM) das dietas experimentais com três níveis de alfafa fornecidas aos cordeiros alimentados em creep feeding

Table 1 - Chemical and percentual composition and crude protein $(C P)$ and metabolizable energy (ME) contents of experimental diets fed to lambs on creep feeding with three levels of alfalfa

\begin{tabular}{lccc}
\hline & \multicolumn{3}{c}{$\begin{array}{c}\text { Níveis de feno de alfafa (\%) } \\
\text { Alfalfa hay levels (\%) }\end{array}$} \\
\cline { 2 - 4 } $\begin{array}{l}\text { Ingrediente } \\
\text { Ingredient }\end{array}$ & 0 & 15 & 30 \\
\hline $\begin{array}{l}\text { Milho } \\
\text { Corn }\end{array}$ & 65 & 54 & 43 \\
$\begin{array}{l}\text { Farelo de soja } \\
\text { Soybean meal }\end{array}$ & 34 & 30 & 26 \\
$\begin{array}{l}\text { Feno de alfafa } \\
\text { Alfalfa hay }\end{array}$ & - & 15 & 30 \\
$\begin{array}{l}\text { Sal mineral } \\
\text { Mineral salt }\end{array}$ & 1 & 1 & 1 \\
$\begin{array}{l}\text { Proteína bruta } \\
\text { Crude protein }\end{array}$ & 20,95 & 20,90 & 20,84 \\
$\begin{array}{l}\text { EM Mcal EM/kg MS } \\
\text { ME Mcal ME/kg DM }\end{array}$ & 3,13 & 2,96 & 2,79 \\
\hline
\end{tabular}

de 24,88; 25,45; e 23,41 kg para os tratamentos 0,15 e $30 \%$ de feno de alfafa na ração, respectivamente. Estes animais passaram por uma adaptação de 10 dias, permanecendo durante todo o confinamento com a mesma ração do creep feeding. Os animais do tratamento sem acesso ao creep feeding não foram confinados. Os animais do tratamento $0 \%$ de alfafa receberam feno de Tifton 85 à vontade.

Para avaliar o desempenho nessa fase, utilizou-se o delineamento experimental inteiramente casualizado em esquema fatorial $3 \times 2$, sendo três níveis de feno de alfafa e dois sexos.

No segundo ano, o experimento foi realizado em apenas uma fase, ou seja, os animais permaneceram no creep feeding até atingirem o peso vivo final, avaliando em delineamento experimental inteiramente casualizado em esquema fatorial $(2 \times 2)$, duas formas físicas da ração (farelada e peletizada) e dois sexos.

No total, foram utilizadas 32 ovelhas com suas crias, 3/4 mestiços Suffolk, com parto simples. Após o nascimento, as crias foram pesadas e colocadas junto com as ovelhas em piquetes de gramínea estrela branca (Cynodon plectostachyus). Para cada tratamento foram utilizados dois piquetes de $2750 \mathrm{~m}^{2}$. Para a avaliação de desempenho, foram utilizados dez cordeiros inteiros e seis cordeiras por tratamento. Os cordeiros foram avaliados até atingirem os pesos de abate de 26 e $28 \mathrm{~kg}$. As fêmeas retornaram ao rebanho com peso vivo de $28 \mathrm{~kg}$. O período de nascimento dos animais foi de 25 de junho a 13 de julho de 1998.

A dieta farelada ou peletizada constituiu-se de $62 \%$ de milho, $22 \%$ de farelo de soja, $15 \%$ de feno de alfafa e $1 \%$ de sal mineral. A composição em PB e EM foi de 17,99\% de PB e 2,96 Mcal de EM/kg, respectivamente.

As ovelhas receberam ração para lactação duas vezes ao dia e feno de Tifton 85 à vontade, para atender as exigências de ovelhas em lactação (NRC, 1985). As dietas dos cordeiros foram fornecidas em duas refeições diárias (8 e 16 h).

Com o objetivo de adaptar os cordeiros à ração peletizada, forneceu-se nos primeiros 15 dias experimentais uma proporção de 50:50 de ração farelada e peletizada. A pesagem dos cordeiros e das ovelhas foi realizada a cada 14 dias juntamente com a coleta de fezes dos cordeiros e das ovelhas, para exame parasitológico (OPG).

As análises estatísticas dos dados referentes ao acompanhamento temporal do peso vivo dos cordeiros criados em sistema de creep feeding, submetidos a 
diferentes níveis de feno de alfafa na dieta (Experimento 1) ou às duas formas físicas da ração (Experimento 2), foram realizadas considerando-se modelos lineares de efeitos mistos para dados longitudinais (VERBEK e MOLENBERGHS, 1997), incluindo-se como fixos os efeitos principais referentes ao tipo de ração, sexo e tempo, bem como as possíveis interações e como aleatório o efeito de cada indivíduo (cordeiro).

Todos os cálculos foram efetuados utilizando-se o procedimento MIXED do programa computacional SAS (LITTELL et al., 1996). Os resultados foram discutidos no nível de 5\% de significância pelo teste de Tukey.

\section{Resultados e Discussão}

No primeiro ano experimental, os pesos médios ao nascimento dos cordeiros foram 4,3 e 4,8 kg, para fêmeas e machos, respectivamente. Na Tabela 2, encontram-se os resultados de peso vivo dos cordeiros alimentados em creep feeding, correspondentes à primeira fase do experimento.

Tabela 2 - Regressões da variável peso vivo de cordeiros alimentados em creep feeding, em função do tempo (dias), segundo o sexo e os níveis de feno de alfafa

Table 2 - Live weight regression analysis of lambs fed on creep feeding, in function of time (days), according to sex and alfalfa hay levels

\begin{tabular}{lcc}
\hline $\begin{array}{l}\text { Tratamento } \\
\text { Treatment }\end{array}$ & $\begin{array}{c}\text { Sexo } \\
\text { Sex }\end{array}$ & $\begin{array}{c}\text { Regressão } \\
\text { Regression }\end{array}$ \\
\hline $\begin{array}{l}\text { Sem creep } \\
\text { Withoutcreep }\end{array}$ & $\begin{array}{c}\text { Macho } \\
\text { Male }\end{array}$ & $\hat{\mathrm{Y}}=5,7406+0,2243^{(1)} \mathrm{d}$ \\
FA 0\% & Macho & $\hat{\mathrm{Y}}=3,1382+0,3883 \mathrm{~d}$ \\
AH 0\% & Male & \\
FA 15\% & Macho & $\hat{\mathrm{Y}}=4,8769+0,3674 \mathrm{~d}$ \\
AH 15\% & Male & \\
FA 30\% & Macho & $\hat{\mathrm{Y}}=3,2839+0,3594 \mathrm{~d}$ \\
AH 30\% & Male & \\
Sem creep & Fêmea & $\hat{\mathrm{Y}}=6,6491+0,1815 \mathrm{~d}$ \\
Without creep & Female & \\
FA 0\% & Fêmea & $\hat{\mathrm{Y}}=2,0216+0,3456 \mathrm{~d}$ \\
AH 0\% & Female & \\
FA 15\% & Fêmea & $\hat{\mathrm{Y}}=4,4301+0,3246 \mathrm{~d}$ \\
AH 15\% & Female & \\
FA 30\% & Fêmea & $\hat{\mathrm{Y}}=3,5027+0,3166 \mathrm{~d}$ \\
AH 30\% & Female &
\end{tabular}

FA \%: $0 \%$ de alfafa na ração; FA $15 \%: 15 \%$ de feno de alfafa na ração; FA 30\%: $30 \%$ de feno de alfafa na ração.

(1) Ganho médio diário.

AH \%: $0 \%$ alfalfa on diet; $A H$ 15\%: $15 \%$ alfafa hay on diet; $A H 30 \%: 30 \%$ alfalfa hay on diet.

(1) Daily live weight gain.
A partir da comparação dos coeficientes de regressão, constatou-se que os machos apresentaram maior ganho de peso do que as fêmeas $(\mathrm{p}<0,05)$, da ordem de 42,8 g a mais por dia. Verificou-se, também, que a suplementação favoreceu o ganho de peso $(\mathrm{p}<0,05)$, com $147,4 \mathrm{~g}$ a mais por dia. O ganho de peso médio diário dos machos e fêmeas com acesso ao creep feeding foi de 372 e 329 g/dia, enquanto os animais sem acesso apresentaram ganhos de 224 e $181 \mathrm{~g} /$ dia, respectivamente.

Os animais que tiveram acesso ao creep feeding foram desmamados aos 56 dias com peso vivo superior $(24,58$ e $21,74 \mathrm{~kg}$ para machos e fêmeas, respectivamente) àqueles dos animais que não tiveram acesso ao creep feeding, cujos pesos foram 18,30 e $16,81 \mathrm{~kg}$ ao desmame para machos e fêmeas, respectivamente. Estes dados evidenciam a importância da suplementação na fase de aleitamento, considerando ainda que, no desmame precoce (45 dias), ocorre depressão no crescimento logo após o desmame, podendo ser mais pronunciado em cordeiros sem suplementação. POE et al. (1969) verificaram que cordeiros Hampshire Down que receberam leite e volumoso apresentaram menor estresse pós-desmama; porém, na décima segunda semana, os cordeiros que receberam concentrado e leite apresentaram maior ganho em peso em relação aos que receberam exclusivamente leite e leite mais volumoso.

Com relação ao ganho médio diário no creep feeding, os dados foram superiores aos obtidos por DONEY et al. (1988), que, avaliando cordeiros da raça Scottish Blackface em creep feeding, obtiveram ganho médio diário de 118 e $148 \mathrm{~g} /$ dia, para dietas com 12,2 e 17,6\% de PB, bem como aos de OTTO et al. (1994), que obtiveram desempenho de cordeiros com acesso ao creep feeding de 190 e $182 \mathrm{~g} /$ dia, desmamados aos 45 e aos 60 dias, respectivamente, e próximos aos obtidos por SILVA et al. (1998), em cordeiros mestiços Texel x Ideal com ganhos de $351 \mathrm{~g}$ até o desmame (45 dias).

O consumo médio diário de ração no creep feeding elevou-se conforme o aumento da inclusão de feno de alfafa na ração, sendo para os níveis 0,15 e $30 \%$ de feno de alfafa na ração da ordem de 438,475 e $529 \mathrm{~g} /$ dia, respectivamente. Entretanto, não houve diferenças $(p>0,05)$ para ganho de peso em relação aos níveis de feno de alfafa na dieta dos animais (Tabela 2). Houve aumento no consumo de ração, proporcional ao decréscimo nos níveis de EM da ração.

JOHNSTON (1992) observou que os cordeiros criados em creep feeding iniciaram o consumo de 
ração no sétimo dia, com aumento significativo a partir da quarta semana, sendo que na quinta semana os cordeiros consumiram, em média, $253 \mathrm{~g} / \mathrm{dia}$, inferiores ao do presente experimento.

$\mathrm{Na}$ Tabela 3, encontram-se os resultados da segunda fase do experimento, quando os cordeiros foram confinados após o desmame.

No estudo do desenvolvimento ponderal de cordeiros terminados em confinamento, verificou-se que os machos apresentaram maior ganho de peso por dia $(\mathrm{p}<0,05)$ do que as fêmeas $(33,0 \mathrm{~g} / \mathrm{dia})$. GASTALDI e SILVA (1998) também observaram em cordeiros confinados ganho de peso superior nos machos, em especial os que receberam ração com $70 \%$ de concentrado.

Em relação à resposta aos níveis de feno de alfafa nas dietas, verificou-se que não houve efeito $(p>0,05)$ no ganho de peso das fêmeas; entretanto, para os machos, a inclusão do feno aumentou o ganho de peso dos animais ( $<<0,01)$, sendo que a dieta com $15 \%$ de feno permitiu desempenho superior $(\mathrm{p}<0,05)$ em relação a com $30 \%$.

Como para os machos a inclusão de diferentes níveis de feno de alfafa na ração influenciou o ganho de peso dos animais, realizou-se um estudo de regressão. As médias de peso vivo utilizadas para o estudo da regressão referem-se somente à primeira pesagem dos machos realizada no confinamento, feita após a adaptação, tendo em vista que, 12 dias após a primeira pesagem, todos os machos do tratamento com $15 \%$

Tabela 3 - Regressão da variável peso vivo de cordeiros terminados em confinamento, em função do tempo em dias (d), segundo os níveis de feno de alfafa (FA) na ração

Table 3 - Live weight regression analysis of lambs finished in feedlot, in function of time (days), according to alfalfa hay $(A H)$ levels in the diet

\begin{tabular}{|c|c|c|}
\hline $\begin{array}{l}\text { Nível de FA (\%) } \\
\text { AH level (\%) }\end{array}$ & $\begin{array}{l}\text { Sexo } \\
\text { Sex }\end{array}$ & $\begin{array}{l}\text { Regressão } \\
\text { Regression }\end{array}$ \\
\hline 0 & $\begin{array}{l}\text { Macho } \\
\text { Male }\end{array}$ & $\hat{Y}=14,1078+0,1900 d$ \\
\hline 15 & $\begin{array}{l}\text { Macho } \\
\text { Male }\end{array}$ & $\hat{\mathrm{Y}}=6,8356+0,3262 \mathrm{~d}$ \\
\hline 30 & $\begin{array}{l}\text { Macho } \\
\text { Male }\end{array}$ & $\hat{Y}=9,4604+0,2568 d$ \\
\hline 0 & $\begin{array}{l}\text { Fêmea } \\
\text { Female }\end{array}$ & $\hat{Y}=10,0953+0,1935 c$ \\
\hline 15 & $\begin{array}{l}\text { Fêmea } \\
\text { Female }\end{array}$ & $\hat{\mathrm{Y}}=8,7065+0,2193 \mathrm{~d}$ \\
\hline 30 & $\begin{array}{l}\text { Fêmea } \\
\text { Female }\end{array}$ & $\hat{\mathrm{Y}}=7,8224+0,2238 \mathrm{~d}$ \\
\hline
\end{tabular}

de feno de alfafa na ração foram abatidos. No estudo de regressão polinomial para níveis de feno de alfafa $(\mathrm{X})$, verificou-se efeito significativo $(\mathrm{p}<0,05)$ para regressão quadrática $\left(137,5+21,0666 \mathrm{X}-0,5633 \mathrm{X}^{2}\right)$, com $\mathrm{R}^{2}=1,0$. O ponto de máxima ficou em $18,7 \%$ de inclusão de feno de alfafa na ração, com ganho de peso esperado neste nível de inclusão de 334,45 g/dia.

O consumo médio de ração (MS) por cordeiro no confinamento ficou em 986,6; 956,3; e 1090,3 g/dia para os níveis 0,15 e $30 \%$ de feno de alfafa, respectivamente.

Os cordeiros machos atingiram peso vivo final (30 a $32 \mathrm{~kg}$ ) com as seguintes idades: 78, 82 e 86 dias para os níveis 15,30 e $0 \%$ de inclusão de feno de alfafa na ração. Portanto, o período médio de confinamento ficou em 22, 56 e 30 dias para os tratamentos 15,30 e $0 \%$ de inclusão de feno de alfafa, respectivamente. Todas as fêmeas atingiram aos 99 dias de idade os pesos de 30 a $32 \mathrm{~kg}$.

Os valores de ganho de peso foram superiores aos obtidos por SILVA et al. (1998), que, estudando cordeiros confinados, observaram ganhos de 165 e $182 \mathrm{~g} / \mathrm{dia}$ para aqueles abatidos com 28 e $33 \mathrm{~kg}$ de peso vivo, respectivamente, e por MACEDO (1998), que obteve ganhos de 144 e $137 \mathrm{~g} /$ dia do desmame ao abate para cordeiros terminados em confinamento e em pastagem, respectivamente, sendo que os cordeiros confinados atingiram o peso de abate $(30 \mathrm{~kg})$ aos 219 dias e os terminados em pastejo, aos 258 dias. Entretanto, os resultados foram inferiores aos encontrados por ORSKOV etal.(1971), que avaliaram cordeiros ScottishHalfbred x Suffolk, confinados após o desmame dos 15 aos $40 \mathrm{~kg}$ recebendo dietas à base de milho e cevada laminada, com ganhos de 428 e $430 \mathrm{~g} /$ dia e conversão alimentar de 2,33 e 2,22, respectivamente.

O desempenho observado neste experimento mostrou-se superior aos registrados na literatura, valores estes somente obtidos em cordeiros de raças especializadas para produção de carne, com aptidão para altos níveis de produtividade. SILVA (1997) citou como vantagens da raça Suffolk a precocidade, excelente ganho de peso dos cordeiros e ótimo rendimento de carcaça.

No segundo ano experimental, os pesos médios ao nascimento dos cordeiros foram 4,1 e 4,7 kg para fêmeas e machos, respectivamente. Neste experimento, devido ao elevado ganho de peso dos cordeiros, estes não foram confinados, permanecendo no creep até atingirem o peso de abate.

A partir da comparação dos coeficientes de regressão, constatou-se (Tabela 4) que os machos 
apresentaram maior ganho de peso do que as fêmeas ( $\mathrm{p}<0,05)$, com 55,4 g/dia a mais e a ração peletizada propiciou maior desenvolvimento dos animais $(\mathrm{p}<0,05)$ quando comparada à ração farelada (23,8 g a mais/dia).

O consumo médio da ração (MS) foi de 359,63 e $368,13 \mathrm{~g} /$ dia para as rações farelada e peletizada, respectivamente.

Para os machos abatidos com $28 \mathrm{~kg}$ de peso vivo, a idade média de abate ficou em 60 dias para o tratamento com ração peletizada e 64 dias para o tratamento com ração farelada. Para os machos abatidos com $26 \mathrm{~kg}$ de peso vivo, a idade média de abate variou de 55 dias para ração peletizada a 59 dias para ração farelada. As fêmeas atingiram o peso de $28 \mathrm{~kg}$ aos 72 e 77 dias para os tratamentos com ração peletizada e farelada, respectivamente.

Os valores obtidos para ganho de peso foram superiores aos encontrados por SAÑUDO et al. (1998), que obtiveram em animais da raça Rasa Aragonesa ganhos de 222 g para cordeiros desmamados com 40 dias e confinados e $232 \mathrm{~g} /$ dia para aqueles que permaneceram com as ovelhas até atingirem o peso de abate (22,1 kg para ambos os tratamentos). Ambos os grupos atingiram o peso de abate com 78 dias de idade e SUMMERS et al. (1978), que obtiveram ganhos de 273,3 g/dia para cordeiros não desmamados, em pastejo, com suplementação concentrada.

O melhor desempenho de cordeiros suplementados com ração peletizada também foi obtido por CASEY e WEBB (1995), que registraram ganho médio de $204 \mathrm{~g} /$ dia para cordeiros confinados com ração farelada e $283 \mathrm{~g} /$ dia com ração peletizada.

Tabela 4 - Regressões da variável peso vivo de cordeiros terminados em creep feeding, em função do tempo (dias), segundo o sexo e a forma física da ração

Table 4 - Liveweight regression analysis of lambs finished in creep feeding related to time (days), according to sex and diet physical form

\begin{tabular}{lcc}
\hline $\begin{array}{l}\text { Ração } \\
\text { Diet }\end{array}$ & $\begin{array}{c}\text { Sexo } \\
\text { Sex }\end{array}$ & $\begin{array}{c}\text { Regressão } \\
\text { Regression }\end{array}$ \\
\hline $\begin{array}{l}\text { Farelada } \\
\text { Ground }\end{array}$ & $\begin{array}{c}\text { Macho } \\
\text { Male }\end{array}$ & $\hat{\mathrm{Y}}=4,3793+0,3688 \mathrm{~d}$ \\
$\begin{array}{l}\text { Peletizada } \\
\text { Pelleted }\end{array}$ & $\begin{array}{c}\text { Macho } \\
\text { Male }\end{array}$ & $\hat{\mathrm{Y}}=4,4345+0,3926 \mathrm{~d}$ \\
$\begin{array}{l}\text { Farelada } \\
\text { Ground }\end{array}$ & Fêmea & $\hat{\mathrm{Y}}=3,9345+0,3134 \mathrm{~d}$ \\
$\begin{array}{l}\text { Peletizada } \\
\text { Pelleted }\end{array}$ & Female & \\
\hline
\end{tabular}

O consumo foi de $0,933 \mathrm{~kg}$ para farelada e $1,085 \mathrm{~kg}$ para peletizada. O tempo de permanência dos animais no confinamento foi de 66 e 86 dias para as rações peletizada e farelada, respectivamente.

Entretanto, NICHOLS et al. (1992) registraram melhor conversão alimentar para cordeiros recebendo ração no sistema livre escolha, quando comparados ao fornecimento de ração peletizada (70\% milho e $30 \%$ feno de alfafa). Os autores sugerem que os cordeiros que receberam ração no sistema livre escolha ingeriram menos concentrado, resultando em menor acidose.

HATFIELD et al. (1997), ao compararem alfafa peletizada e moída, não verificaram diferenças no desempenho dos cordeiros, porém aqueles que receberam alfafa moída apresentaram maior taxa de amido fecal.

Nas regiões de clima temperado, a terminação de cordeiros em pastagem de alta qualidade ou em pastagens com suplementação tem sido relatada por alguns autores como a mais eficiente em relação ao confinamento na terminação de cordeiros. McCLURE et al. (1994) obtiveram melhor desempenho e características de carcaça de cordeiros em pastagem de alfafa, quando comparados com animais confinados. ELY et al. (1979) verificaram melhor desempenho de cordeiros terminados em pastagem de trevo e bluegrass, que tinham à disposição suplementação concentrada (13\% PB), quando comparados aos cordeiros terminados somente a pasto ou confinados.

Verificou-se, neste trabalho, portanto, que a suplementação de cordeiros mestiços Suffolk desde o nascimento promoveu melhor desempenho destes, reduzindo a idade de abate. A terminação dos cordeiros em creep feeding resultou na eliminação da fase de terminação em confinamento, recomendado em sistemas intensivos.

\section{Conclusões}

O uso do creep feeding é fundamental no aumento da produtividade da ovinocultura, por interferir acentuadamente na redução da idade de abate dos cordeiros.

$\mathrm{O}$ feno de alfafa pode ser incluído na ração inicial de cordeiros até o nível máximo de 18,7\%.

A utilização de ração na forma peletizada, apesar de apresentar maior consumo, é mais vantajosa do que na forma farelada, por refletir em melhores índices de desempenho dos cordeiros, com a diminuição da idade de abate dos mesmos. 


\section{Referências Bibliográficas}

CASEY, N.H., WEBB, E.C. 1995. Influence of dietary energy levels and form of diet on composition of fatty acids in subcutaneous adipose tissue of wethers. Small Ruminants Res., 18:125-32.

DONEY, J.M., MILNE, J. A., MAXWELL, T.J. et al. 1988. The effects of live weight at weaning on growth rate and carcass composition at differents stages of maturity in Scottish Blackface lambs fed on two different diets. Anim. Prod., 47:401-09.

ELY, D.G., GLENN,B.P., MAHYUDDIN, M. 1979. Drylot vs pasture: early-weaned lamb performance to two slaughter weights. J. Anim. Sci., 48:32-37.

GASTALDI, K.A., SILVA SOBRINHO, A.G. Desempenho de ovinos $f 1$ Ideal x Ile de France em confinamento com diferentes relações concentrado:volumoso. In: REUNIÃO ANUAL DA SOCIEDADE BRASILEIRA DE ZOOTECNIA, 35, 1998, Botucatu, SP. Anais... Botucatu: SBZ, 1998. p.257-59.

HATFIELD, P., HOPKINS, J.A., PRITCHARD, G.T. et al. 1997. The effects of amount of whole barley, barley bulk density, and form of roughage on feedlot lamb performance, carcass characteristics, and digesta kinetics. J. Anim. Sci., 75:3353-66.

JOHNSTON, C. 1992. Influence of milk and grain-based creep feed formulations on feed intake and weight gain of suckling lams to be weaned at 28 days of age. Sheep Res. J., 18(3):106-11.

LITTELL, R.C., MILLIKEN, G.A., STROUP, W.W. et al. 1996. SAS ${ }^{\circledR}$ system for mixed models. Cary, NC: SAS Institute Inc. $633 \mathrm{p}$.

MACEDO, F.A.F. Desempenho e caracteríticas de carcaças de cordeiros Corriedale e mestiços Bergamácia x Corriedale e Hampshire Down $x$ Corriedale, terminados em pastagem e confinamento. Botucatu, SP: FMVZ - UNESP, 1998. 72p. Tese (Doutorado em Zootecnia) - Universidade Estadual Paulista, 1998.

McClURE, K.E., VAN KEUREN, R.W., ALTHOUSE, P.G. 1994. Performance and carcass characteristics of weaned lambs either grazed on orchardgrass, ryegrass, or alfalfa or fed all-concentrate diets in drylot. J. Anim. Sci., 72:3230-3237.
NATIONAL RESEARCH COUNCIL - NRC. 1985. Nutrient requeriments of sheep. Washington: National Academy Press. 99p.

NICHOLS, M.E., FITCH, G.Q., McCOLLUM, F.T. 1992. Effect of ration presentation upon performance of feedlot lambs. Anim. Res. Report, p.355-59.

ORSKOV, E.R., FRASER, C., GILL, J.C. et al. 1971. The effect an intensive production system of type of cereal and time of weaning on the performance of lambs. Anim. Prod., 13:485-92.

OTTO, C., BONA, A.F.O., SÁ, J.L., DEGASPERI, A. Efeito do desmame aos 45 e 60 dias de idade no desenvolvimento de cordeiros. In: CONGRESSO BRASILEIRO DE MEDICINA VETERINÁRIA, 23, 1994. Olinda, PE. Anais... Olinda: CBMV, 1994. p.55.

POE, S.E., DEWEESE, W.P., MITCHELL, G.E. 1969. Effect of pre-weaning diet on the growth and development of earlyweaned lambs. J. Anim. Sci., 28:401-05.

SAÑUDO, C., SIERRA, J.L., MARTINS, L. et al. 1998. Influence of weaning on carcass quality, fatty acid composition and meat quality in intensive lamb production systems. J. Anim. Sci., 66:175-87.

SILVA, A.G. 1997. Criação de ovinos. Jaboticabal: FUNEP. 230p.

SILVA, L.F., PIRES, C.C., FULBER, M.E. et al. Desempenho de cordeiros inteiros confinados. In: REUNIÃO ANUAL DA SOCIEDADE BRASILEIRA DE ZOOTECNIA, 35, 1998, Botucatu, SP. Anais... Botucatu: SBZ, 1998. p.254.

SUMMERS, R.L., KEMP, J.D., ELY, D.G. et al. 1978. Effects of weaning feeding systems and sex of lamb on lamb carcass characteristics and palatability. J. Anim. Sci., 47(3):623-29.

VERBEK, G., MOLENBERGHS, G. 1997. Linear mixed models in practice: a SAS-oriented approach. New York: Springer. 306p.

Recebido em: $17 / 08 / 00$

Aceito em: 20/02/01 